\title{
Modelling mammalian energetics: the heterothermy problem
}

\author{
Danielle L. Levesque ${ }^{1 *}$, Julia Nowack ${ }^{2}$ and Clare Stawski ${ }^{3}$
}

\begin{abstract}
Global climate change is expected to have strong effects on the world's flora and fauna. As a result, there has been a recent increase in the number of meta-analyses and mechanistic models that attempt to predict potential responses of mammals to changing climates. Many models that seek to explain the effects of environmental temperatures on mammalian energetics and survival assume a constant body temperature. However, despite generally being regarded as strict homeotherms, mammals demonstrate a large degree of daily variability in body temperature, as well as the ability to reduce metabolic costs either by entering torpor, or by increasing body temperatures at high ambient temperatures. Often, changes in body temperature variability are unpredictable, and happen in response to immediate changes in resource abundance or temperature. In this review we provide an overview of variability and unpredictability found in body temperatures of extant mammals, identify potential blind spots in the current literature, and discuss options for incorporating variability into predictive mechanistic models.
\end{abstract}

Keywords: Endothermy, Torpor, Heterothermy, Mechanistic models, Body temperature, Hibernation, Mammal,

\section{Background}

Global climate change has provided a sense of urgency to the importance of understanding the interactions between organisms and environmental temperatures. As we seek to improve the accuracy of predicting organismal responses to changes in climate, emphasis is being placed on mechanistic models that rely on an in-depth understanding of the thermoregulatory physiology and energetics of a species [1-6]. To date, however, the bulk of these models have been built and tested on ectothermic organisms [7-9], while research on endotherms has lagged behind [10]. This is partly due to deficiencies in understanding the mechanisms of the relationship between environmental temperatures and energy metabolism in endotherms [8, 11-13]. With a few notable exceptions (eg. [14]), ectotherms predominantly rely on external sources of heat production and therefore have a relatively consistent, and thus predictable, relationship between ambient temperature $\left(T_{a}\right)$ and body temperature $\left(T_{b}\right)[9,15,16]$. By contrast, endotherms can generate heat using metabolism and as such $\mathrm{T}_{\mathrm{b}}$ is generally independent of $\mathrm{T}_{\mathrm{a}}[17]$.

\footnotetext{
* Correspondence: danielle.l.levesque@maine.edu

'School of Biology and Ecology, University of Maine, Orono, ME, USA04469 Full list of author information is available at the end of the article
}

From its conception, the comparative study of endothermic thermoregulation has been based on the assumption that $T_{b}$ is maintained at a constant and elevated level $[7,18]$. One of the most common ways to quantify the relationship between $T_{b}$ and $T_{a}$ in mammals, and in endotherms in general, is the ScholanderIrving model [18]. Also called thermal profiles, the Scholander-Irving model requires measuring resting metabolic rate (preferably from fasted, non-reproductive individuals, during their rest-phase) over a series of environmental temperatures to identify the range of $T_{a} s$ over which metabolic rate remains minimal, referred to as the thermoneutral zone (TNZ) [18]. At temperatures below the lower critical limit of the TNZ, thermal conductance (the rate at which heat is lost from the body, and the inverse of insulation) is at a minimum and energetically costly means of heat production (primarily shivering and non-shivering thermogenesis) are used to maintain $\mathrm{T}_{\mathrm{b}}$. Similarly, as temperatures increase above the upper critical limit, where thermal conductance is maximised, metabolism increases as energetically costly means of evaporative cooling (panting and sweating) are employed to maintain a stable $\mathrm{T}_{\mathrm{b}}[16]$.

Existing mechanistic models have incorporated the Scholander-Irving model, and its assumptions, into a set 
of predictive equations used to calculate the costs of thermoregulation under various environmental conditions [13, 19-21]. However, these models present a somewhat simplistic version of mammalian energetics in relation to climate. Often, it is assumed that the animal is actively defending a set $\mathrm{T}_{\mathrm{b}}$, and therefore the models do not take into account the potential effects of variable $\mathrm{T}_{\mathrm{b}}$ (but see [22], for a notable exception). Strict homeothermy (a constant, often elevated $\mathrm{T}_{\mathrm{b}}$ ) is not the norm and, as we will demonstrate in this review, many endotherms vary their $\mathrm{T}_{\mathrm{b}}$ considerably. While some species only show slight daily changes, with higher $T_{b}$ during activity than at rest, others employ larger decreases in $\mathrm{T}_{\mathrm{b}}$ during the rest phase [23-27], or thermoconform, which is accompanied by a decrease in metabolism, by either reducing $\mathrm{T}_{\mathrm{b}}$, (torpor, [28-30]) or increasing $\mathrm{T}_{\mathrm{b}}$ (hyperthermia, reviewed in [31]). When environmental temperatures rise above $T_{b}$, evaporative cooling is often the only means of maintaining a stable $\mathrm{T}_{\mathrm{b}}$. To conserve water and avoid dehydration, some endotherms employ facultative hyperthermia (also referred to thermoconforming or heat storage) at high $\mathrm{T}_{\mathrm{a}}$ and increase their $\mathrm{T}_{\mathrm{b}}$ to sublethal temperatures [31-33]. Increases in $T_{b}$ reduces both the energetic and water costs of cooling mechanisms [32, 34, 35].

Variable $T_{b}$ is widespread in mammals, and both habitat and evolutionary history have a large influence on the thermoregulatory characteristics of endotherms $[10,29,36]$. Energy usage in relation to climate is further affected by phylogeny, activity level, microclimate selection, reproductive status, and energy availability $[13,21$, 37-40]. Due to fundamental differences in thermoregulation between mammals and birds, we will focus predominantly on mammals in this review (but see [32, 35, 41] for a discussion on birds). The complexities of predicting metabolism, or even $\mathrm{T}_{\mathrm{b}}$, in relation to differences in $\mathrm{T}_{\mathrm{a}}$ affect the accuracy of predictive mechanistic models. In this review we seek to provide an overview of the variability of thermoregulatory patterns of extant mammals, demonstrate how this variability can complicate predictive mechanistic models, and outline some potential avenues for improvement.

\section{Daily variability in mammalian $T_{b}$}

Many of the existing models that seek to explain species distributions or responses of endothermic animals to climate change are based on the assumption that endotherms maintain a high, relatively stable $\mathrm{T}_{\mathrm{b}}$ throughout a variety of habitats and climatic conditions [18, 42, 43]. Although, when compared with ectothermic species, endotherms generally have significantly reduced variability in $\mathrm{T}_{\mathrm{b}}$, many species show marked differences between active-phase and rest-phase $\mathrm{T}_{\mathrm{b}}$ (Fig. 1) [39, 44, 45]. Mean normothermic $\mathrm{T}_{\mathrm{b}}$ of eutherian mammals lies between 36 and $38{ }^{\circ} \mathrm{C}$ (range $30.5-40.7{ }^{\circ} \mathrm{C}$ ) [46], whereas marsupials and monotremes are generally considered to have lower $\mathrm{T}_{\mathrm{b}} \mathrm{s}$ (mean $35.3{ }^{\circ} \mathrm{C}$, range $30.8-37.4{ }^{\circ} \mathrm{C}$ ) [46-48]. While some species, such as the golden hamster (Mesocricetus auratus) [49] or the swamp rat (Rattus lutreolus; Fig. 1a) only decrease their $\mathrm{T}_{\mathrm{b}} 2-3{ }^{\circ} \mathrm{C}$ during normothermic resting, others, such as treeshrews (Tupaia sp.), show more pronounced $24 \mathrm{~h}$ amplitudes in $\mathrm{T}_{\mathrm{b}}$ (Fig. 1b) [45]. Marsupials, generally have larger daily $\mathrm{T}_{\mathrm{b}}$ amplitudes, and $\mathrm{T}_{\mathrm{b}}$ can vary from between 32 and $34{ }^{\circ} \mathrm{C}$ during normothermic resting, to above $40{ }^{\circ} \mathrm{C}$ during activity, this despite their average $\mathrm{T}_{\mathrm{b}} \mathrm{s}$ being listed at around $35^{\circ}$ C (Fig. 1c) [46, 50, 51]. Basoendotherms (sensu [36]) such as tenrecs (Fig. 1d) and echidnas show the highest level of variability with rest-phase $T_{b}$ closely following $T_{a}$ during most times of the year [52-56].

The cost of endothermy, usually measured via metabolism, varies greatly depending on a number of factors including body size, habitat, resource availability, climatic conditions, and activity patterns [57-59]. A strictly nocturnal activity pattern is the ancestral condition in mammals, and is efficient in warm climates, as it allows animals to save both water and energy [55, 60, 61]. This is especially true for small mammals with low normorthermic $\mathrm{T}_{\mathrm{b}} \mathrm{s}\left(\sim 32-35{ }^{\circ} \mathrm{C}\right)$, as a relatively high $\mathrm{T}_{\mathrm{b}}$ is maintained passively during the day-time rest-phase, and activity can offset most of the potential thermoregulatory costs at night $[38,55,61]$. Conversely, in colder climates where most small-bodied species rest in thermally insulated burrows, diurnal activity can reduce overall energy expenditure by lowering the need for thermogenesis during the active period [13, 62]. The relative energetic costs and benefits of a nocturnal or diurnal activity pattern have so far mostly been discussed in single species studies, or in hypotheses about the evolution of endothermy [40, 61, 63-65]. Unfortunately, nocturnal and diurnal species, as well as those that do not fit clearly in either category, are usually lumped together in meta-analyses despite facing vastly different environmental conditions.

Daily amplitude changes in $\mathrm{T}_{\mathrm{b}}$ are not solely the result of differences in activity, but appear to be under some level of circadian control, persisting even during continuous rest $[39,66]$. Interestingly, while differences in resting metabolic rates between the active-phase and rest-phase were commonly measured in older studies $[67,68]$, the recent trend toward focusing on the importance of measuring basal metabolism has meant that the energetics of resting during the active-phase is largely ignored. Basal metabolism is measured under a set of restrictive, and often ecologically irrelevant conditions; the animals must be post-absorptive, non-reproductive and not growing $[57,69]$. For species with pronounced, $\mathrm{T}_{\mathrm{a}}$-dependent, decreases in $\mathrm{T}_{\mathrm{b}}$ during normothermic 

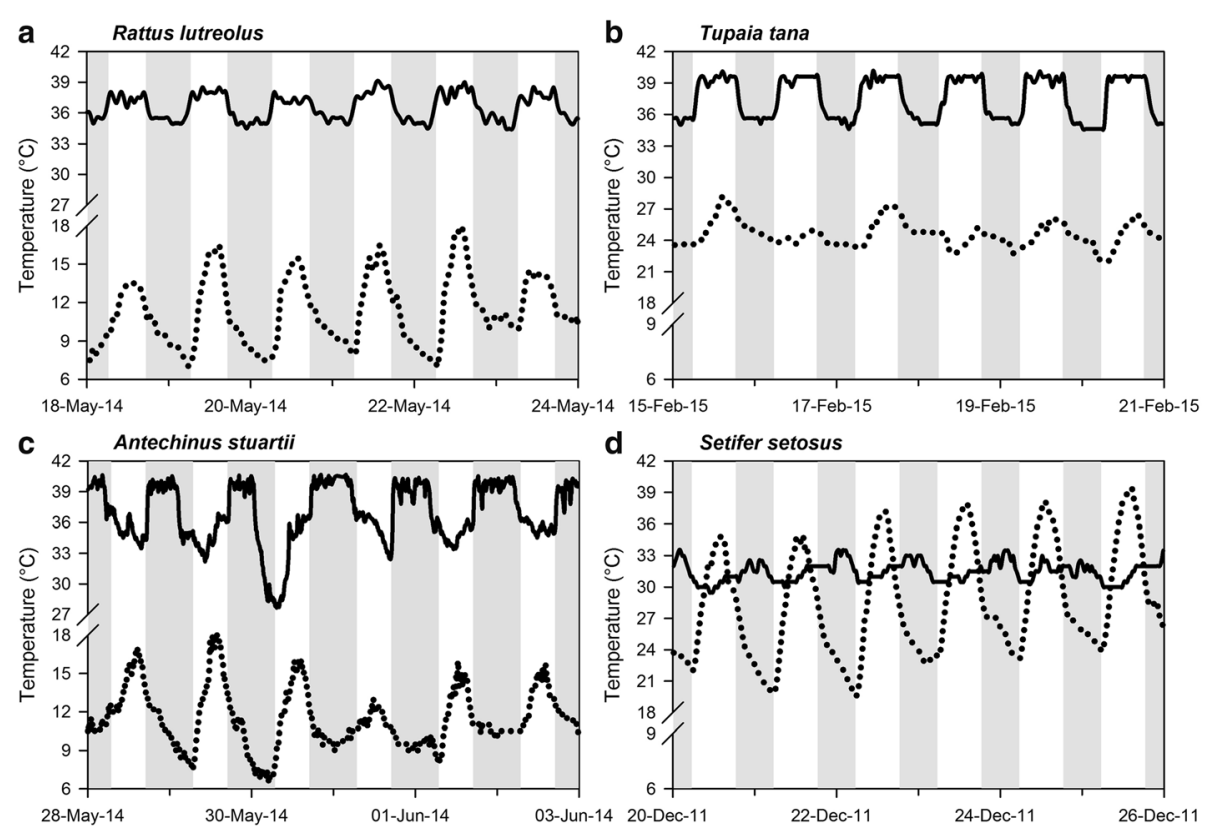

Fig. 1 Sample body temperature traces (solid lines) of a single free-ranging individual from several mammal species over a period of 6 days. Also shown are ambient temperature traces (dotted lines) and the nocturnal period is represented by the grey bars and daytime by the white bars. The mammals represented are: (a) an Australian diurnal homeotherm with small daily amplitudes in $\mathrm{T}_{\mathrm{b}}$ (Rattus lutreolus, Order: Rodentia, Stawski, Körtner, Nowack and Geiser unpublished data); (b) a diurnal homeotherm from Borneo with large daily $T_{\mathrm{b}}$ amplitude (Tupaia tana, Order: Scandentia, Levesque, Tuen and Lovegrove unpublished data); (c) an Australian nocturnal daily heterotherm shown with a torpor bout, low resting $T_{b}$, and high active $T_{b}$ (Antechinus stuartii, Order: Dasyuromorphia, Stawski, Körtner, Nowack and Geiser unpublished data); and (d) a nocturnal basoendotherm from Madagascar (Setifer setosus, Order: Afrosoricida, data from [55])

rest, measuring resting metabolism during the restphase only could grossly underestimate the total baseline energy and water budgets. Pronounced normothermic decreases in rest-phase $T_{b}$ have received considerable attention in the avian literature [41, 70, 71], where decreases in $\mathrm{T}_{\mathrm{b}}$ of $>5{ }^{\circ} \mathrm{C}$ are common, but have been largely ignored in mammals [16].

A major factor that can be overlooked when relying on simplistic mechanistic models is the potential for phenotypic plasticity $[6,72]$. Individuals of one species, or even of one population, can respond differently to an environmental challenge often depending on the condition of the individual. The daily amplitude of $\mathrm{T}_{\mathrm{b}}$ is not $\mathrm{a}$ fixed trait, and can change based on various external factors such as water and energy availability, or competition [25, 73-75]. Camels (Camelus dromedarius) for example maintain a near stable $\mathrm{T}_{\mathrm{b}}$ with only little $\mathrm{T}_{\mathrm{b}}$ variation $\left(\leq 2{ }^{\circ} \mathrm{C}\right)$ and use evaporative cooling when water is available, but increase daily amplitudes in $\mathrm{T}_{\mathrm{b}}$ to more than $6{ }^{\circ} \mathrm{C}$ to conserve water when water stressed [34]. Similarly, Arabian oryx (Oryx leucoryx) show a higher amplitude in daily $\mathrm{T}_{\mathrm{b}}$ during warm dry periods than during periods where water was readily available, which is attributed to low water availability [6]. Flexible increases in $\mathrm{T}_{\mathrm{b}}$ amplitudes by thermoconforming are also employed by small desert mammals in response to high $\mathrm{T}_{\mathrm{a}}$ during the active phase [33]. Some bats in the Australian arid-zone are known to tolerate $T_{a}$ up to $48^{\circ}$ $\mathrm{C}$, with corresponding skin temperatures up to $45.8^{\circ} \mathrm{C}$ [76]. In general, however, our capacity to model mammalian responses to high $T_{a}$ is hindered by a general lack of understanding of upper limits in $\mathrm{T}_{\mathrm{a}}$ tolerance and how flexible they are $[2,8,12,77]$. We have been much better at collecting lower limits of the TNZ than upper (204 versus 93) [78]. Specifically, while increases in $T_{b}$ at high $T_{a}$ have been shown to reduce the energetic costs and increase the efficiency of evaporative cooling in birds and some small desert mammals [32, 33, 79, 80], the interplay between water loss, $T_{b}$ and $T_{a}$ at the upper limits of the TNZ are largely unknown in mammals. Additionally, very little has been done to equate upper limits measured in the lab to conditions experienced by the animals under natural conditions (but see [42, 81]).

In general, endotherms with flexible control over normothermic $T_{b}$ (i.e. thermolabile species) can maximize energy and water use efficiency in response to unpredictable conditions [7, 33, 72, 82]. An extreme example can be found in basoendotherms. In these species, the thermoneutral zone (TNZ) can be difficult to distinguish as $T_{b}$ often closely tracks $T_{a}$, which also blurs the lines between normothermy and torpor [63, 83-85]. What these basoendotherms demonstrate, is that by allowing 
$T_{b}$ to decrease along with $T_{a}$ they reduce the $T_{b}-T_{a}$ gradient, which allows for lower rates of heat loss as well as a widening of the range of $T_{a}$ over which minimum rates of metabolism are measured. Such flexible thermoregulation usually corresponds with a parallel ability to be active over a larger range of $\mathrm{T}_{\mathrm{b}} \mathrm{s}$ [55, 86-89] and is seen to a lesser degree in other endothermic species with high thermolability, but requires more study $[7,77,90$, 91] (Levesque, Lovegrove and Tuen unpublished data). Thermolability, and by extension the characteristics of the TNZ, is not fixed seasonally, however. For example, the reddish-gray mouse lemur (Microcebus griseorufus) not only hibernates during the winter period, but also increases the breadth of their normothermic TNZ during the colder period of the year [92]. In this species the lower critical temperature of the TNZ decreases by $7.5{ }^{\circ} \mathrm{C}$ from summer to winter, which allows the species to keep its energy demands during normothermia constant despite colder $\mathrm{T}_{\mathrm{a}} \mathrm{s}$ during winter [92]. This is a relatively common phenomenon in non-hibernating mammals, but most studies focus on change in insulation rather than change in $\mathrm{T}_{\mathrm{b}}$ as an energy saving mechanism [93-95]. A large body of work exists assessing the evolution of thermal flexibility in ectotherms (reviewed by [15]), but similar approaches have yet to be applied systematically to endotherms $[10,11]$.

\section{Seasonality and unpredictability of mammalian $T_{b}$}

In addition to daily changes in $\mathrm{T}_{\mathrm{b}}$, many mammalian species show changes in their $T_{b}$ between seasons. The most extreme example are the so called 'heterothermic' mammals [29] which can temporarily abandon normothermia and reduce $T_{b}$ and metabolic rate in a state of torpor. Definitions of torpor, and therefore heterothermy, vary throughout the literature. Although most agree that torpor occurs when rest-phase decreases in $\mathrm{T}_{\mathrm{b}}$ are large enough for metabolism to drop below basal levels, the distinction between the two states can sometimes be unclear [52, 91, 96]. In practice, however, torpor is often defined using arbitrary $\mathrm{T}_{\mathrm{b}}$ cut-offs which can underestimate energy saved by $\mathrm{T}_{\mathrm{b}}$ reductions above the torpor cut-off $\mathrm{T}_{\mathrm{b}}$ (see [91], for an in-depth discussion). Similar to the vast differences in the daily $T_{b}$ amplitudes, torpor patterns are highly variable both among and within species (Fig. 2) [10, 29, 36, 53, 97, 98]. However, a decrease in $\mathrm{T}_{\mathrm{b}}$ during winter can not only be observed in heterothermic species, but also, to a lesser degree, in homeothermic species. The homeothermic, European red squirrels (Sciurus vulgaris), for example, lower their $\mathrm{T}_{\mathrm{b}}$ slightly during the winter [99]. This has also been observed in large mammals, such as the red deer (Cervus elaphus) [27] or the Przewalski horse (Equus ferus przewalskii) [100]. Lower $\mathrm{T}_{\mathrm{b}}$ combined with
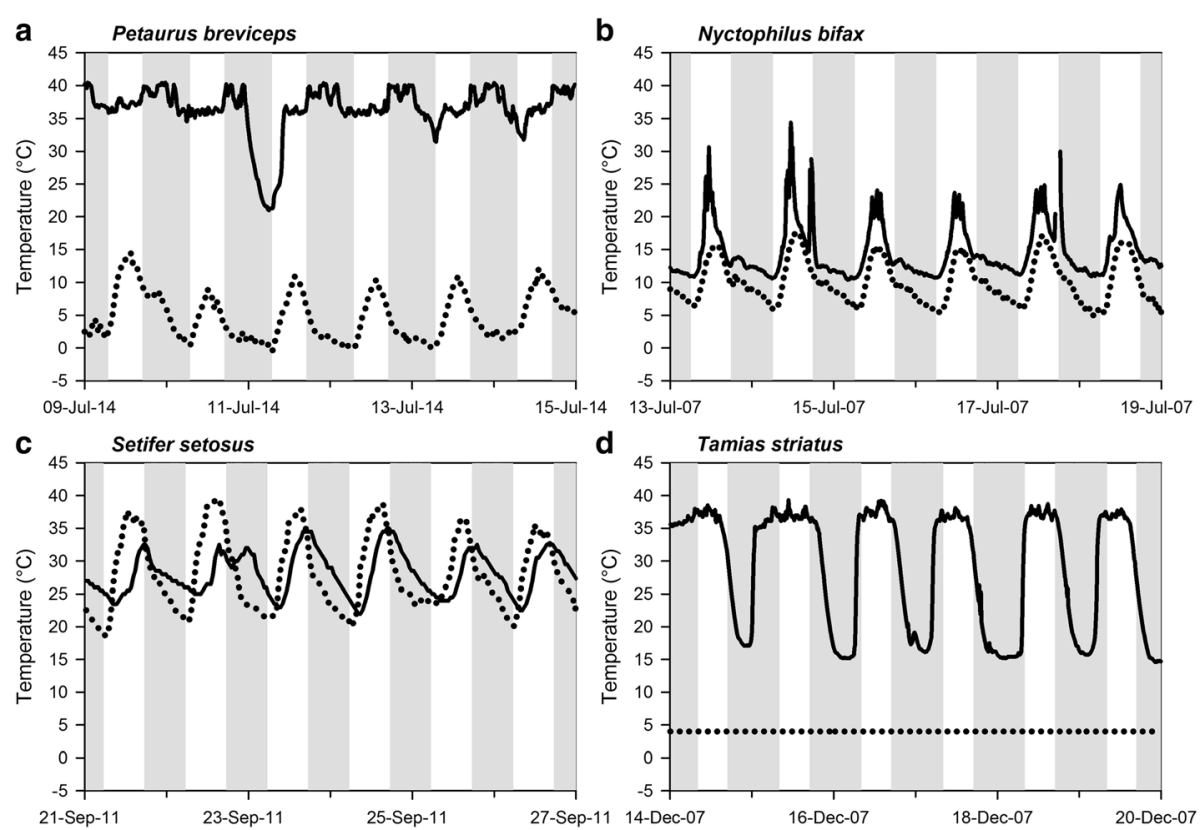

Fig. 2 Examples of variable patterns of torpor expression, defined by reductions in body temperature (solid lines). Ambient temperatures are represented by the dotted lines and night and day are illustrated by the grey and white bars, respectively. Shown are: (a) an Australian daily heterotherm showing one short torpor bout (Petaurus breviceps, Order: Diprotodontia, Nowack unpublished data); (b) an opportunistic hibernator from Australia showing a bout of multiday torpor (Nyctophilus bifax, Order: Chiroptera, Stawski and Geiser unpublished data); (c) a thermo-conforming tropical hibernator from Madagascar during hibernation, the data shown are from a multi-day torpor bout with a single bout of activity occurring the night of the 23rd of September (Setfier setosus, Order: Afrosoricida, data from [55]); and (d) a food storing hibernator from North America showing multiple single day bouts in the laboratory (Tamias striatus, Order: Rodentia, data from [94]) 
increased fur thickness can already lead to substantial energy savings [101], without suffering the potential negative side-effects of torpor [102-106]. Despite the various benefits, torpor use is also associated with costs, for example, a low $T_{b}$ interferes with reproduction as it delays fetal development (reviewed in [107]) and hinders spermatogenesis $[108,109]$. Further costs include slowed locomotor reactions $[89,110]$, decreased sensory perception [110] and increased oxidative stress ([111], but see [112]) therefore there is some benefit to avoiding or reducing torpor if resources are abundant [102].

Traditionally, the study of heterothermy in mammals has focused exclusively on strict categorical classifications: daily heterotherm (torpor less than $24 \mathrm{~h}$ with a relatively high torpid $\mathrm{T}_{\mathrm{b}}$ ), hibernator (multiday torpor bouts at low $\mathrm{T}_{\mathrm{b}}$ ), or homeotherm. However, as thermoregulatory characteristics from more species, especially those from tropical or sub-tropical environments, have been made available, it seems more likely that heterothermy and homeothermy exist on a continuum [36, 53, 113]. Furthermore, by focusing entirely on strict categorical variables, many studies have ignored the potential adaptive benefits to small, non-torpid changes in $T_{b}[7,91]$. It is clear that there exists a high degree of variability in both the level of $\mathrm{T}_{\mathrm{b}}$ (often reported as mean $\mathrm{T}_{\mathrm{b}}$ or set-point $\mathrm{T}_{\mathrm{b}}$ ) and the precision with which it is regulated [10, 29, 36, 46]. Furthermore, it is probable that some degree of heterothermy, and likely variable torpor expression, was the ancestral condition in mammals, and that the high degree of homeothermy in extant species evolved via a highly heterothermic ancestor [36, 53, 114]. Interestingly, whether the variability in $\mathrm{T}_{\mathrm{b}}$ observed is the result of differences in the level of control over $\mathrm{T}_{\mathrm{b}}$, or the side-effect of differences in metabolism and thermal conductance, remains a topic of debate $[58,67,115]$. After reviewing the $\mathrm{T}_{\mathrm{b}}$ of a large number of birds and mammals, Clarke and Rothery [46] came to the conclusion that "... a complex relationship between mass, $\mathrm{T}_{\mathrm{b}}$ and resting metabolic rate and leaves open the intriguing question of whether evolution has adjusted resting metabolic rate through changes in $T_{b}$ or whether $\mathrm{T}_{\mathrm{b}}$ is simply a consequence of resting metabolic rate that has evolved for a particular environment and ecology." This confusion illustrates that we still lack a basic mechanistic understanding of effects of $T_{a}$ on mammalian $\mathrm{T}_{\mathrm{b}}$ and metabolism, something which needs to be taken into consideration when attempting large-scale, multi-species, predictions of responses to climate change.

One potential complication arising from the complex interplay between $T_{b}$, conductance, heat storage, water balance and metabolism, is that $\mathrm{T}_{\mathrm{b}}$ is rarely a good proxy for energy expenditure. Unlike ectotherms, where differences in metabolic rate at different temperatures are largely the result of Arrhenius effects of temperature on metabolism [116], in endotherms the same $T_{b}$ can be the result of a number of energetically differing states including, activity, resting, heating, cooling, or torpidity [52, 91, 117]. Furthermore, behavioural thermoregulation is common and many mammals bask to lower energetic needs during rewarming from torpor [118-123] or to reduce energy costs at cold $\mathrm{T}_{\mathrm{a}} \mathrm{s}$ [26]. For example, tree-roosting long-eared bats (Nyctophilus spp.) frequently roost under exfoliating bark and in particular on the northern facing side of the tree, which receives more sun than the south side in the southern hemisphere [124]. The roosting site, therefore receives sunlight throughout the day and warms up considerably, allowing bats to passively increase their $\mathrm{T}_{\mathrm{b}}$ (Fig. 2b). Indeed, throughout winter the $T_{b}$ of long-eared bats was found to fluctuate daily between $10-20{ }^{\circ} \mathrm{C}$ while remaining torpid. Passive rewarming also allowed bats to save energy on days when they rewarmed to a normothermic $\mathrm{T}_{\mathrm{b}}$ [124]. The benefits of basking has also been shown in small marsupials, where in the field it was confirmed that they are able to move at very low $\mathrm{T}_{\mathrm{b}}$ (as low as $14.6{ }^{\circ} \mathrm{C}$ ) to a basking site to further rewarm in the sun [125-127]. The energetic savings of passive rewarming have been confirmed for bats, marsupials, and primates and arousal costs are decreased by up to $66 \%$ in comparison to active arousals [97, 120, 128]. Basking also plays a role in the thermoregulation of large mammals as indicated by the finding of radiant heat-assisted rewarming during winter in a large mammal, the Alpine ibex (Capra ibex ibex) [26]. Furthermore, depending on the insulative properties of their resting sites, tropical hibernators, such as tenrecs or lemurs (Fig. 2d), may even undergo long-term hibernation in which their $\mathrm{T}_{\mathrm{b}}$ passively tracks $T_{a}$, leading to strong daily fluctuations of $\mathrm{T}_{\mathrm{b}}$ at a low metabolic cost $[52,55,64,97,129]$. The potential for energy and water savings accrued by basking is therefore an important component to energy budgets in species exposed to high $\mathrm{T}_{\mathrm{a}} \mathrm{s}$ or to radiant heat.

For hibernating species the extent of torpor use can also be dependent on body condition or quantity of available food stores [102, 130]. For example, in southern African hedgehogs (Atelerix frontalis) and mouse lemurs, only heavy individuals will undergo hibernation during the winter period, whereas individuals with a lower body mass will only use shorter bouts of torpor [98, 131, 132]. Similarly, throughout summer when $\mathrm{T}_{\mathrm{a}}$ is mild and insects are abundant, individuals of the Australian subtropical/ tropical insectivorous Eastern long-eared bat (Nyctophilus bifax) employ more torpor if they are in better body condition in comparison to individuals in poorer body condition [133]. The authors hypothesized that by using torpor bats can reduce their need to forage, hence reducing their exposure to predators [133]. Importantly, individuals in better body condition can continue to employ torpor and save fat reserves, whereas those in 
poorer body condition likely need to forage extensively to meet their daily energy requirements [132, 133]. But factors other than energy expenditure, such as low water availability (see above) or the reproductive status of an individual can also influence torpor use. While some species abandon torpor use during pregnancy and lactation $[63,138,139]$, others will continue to use torpor to save energy during inclement conditions and even to delay parturition until a more favourable time [107, 140, 141].

When attempting to model how a species will respond to changes in climate, it is important to have an understanding of how often, and for how long, they will be able to employ torpor. For a species with readily predictable torpor bout lengths and hibernation seasons of a set length, such as the Holarctic ground squirrels (family Sciuridae, tribe Marmotini, [142]), this would often cover the winter months only (eg. [143]), although this may also change based on latitude or local climate conditions [144, 145]. Such obligate hibernators, must undergo significant pre-hibernation fattening before entering into torpor [30, 105, 146, 147]. However, many species are able to enter torpor opportunistically throughout the whole year, depending on environmental conditions, and therefore, as we will discuss below, their energetic budget can be difficult to predict [133, 148-152]. Further, recent studies have indicated that torpor use increases in response to unpredictable climatic conditions, such as droughts, fires or storms [51, 110, 153, 154].

Variability in $T_{b}$, and therefore in energy usage, at both the inter- and intra-specific level poses a complication for predictive models. If an animal increases its $T_{b}$, rather than shouldering the costs of increased $T_{a}$ through energetically costly means of defending a set $\mathrm{T}_{\mathrm{b}}$, some of the costs of rising $T_{a}$ may be overestimated. Conversely, in an animal attempting to reduce energy and water usage through torpor, higher $\mathrm{T}_{\mathrm{a}}$ can reduce potential savings $[64,155]$. In contrast to species that use torpor opportunistically, strict hibernators that are less flexible in their physiological response are likely to face negative consequences when surface temperatures rise. Recent studies have indicated that warmer winter temperatures lead to more frequent arousals during hibernation periods [155-157], imposing the risk for small seasonal hibernators to deplete fat reserves before the end of hibernation [158]. Therefore, to be able to accurately predict mammalian responses to climate change, we need to incorporate a level of predictability in heterothermic responses.

To quantify the prevalence of predictability, or unpredictability, in torpor usage within a species, we coded all of the species found in Table 1 of Ruf and Geiser's [29] recent review of mammalian heterotherms as one of three categories (Fig. 3). The first category, 'predictable', was used to classify species which only employed torpor (either via daily heterothermy or hibernation) in response to seasonal shortages of food or water, or cold temperatures. Species which were shown to employ torpor in a highly variable manner or regardless of time of year or season were classed as 'unpredictable'. Finally, species where all the measurements of $\mathrm{T}_{\mathrm{b}}$ were from a single season, or predominantly collected in the laboratory, were classed as 'data deficient'. To date, most species that have been demonstrated to use torpor opportunistically inhabit warmer and more unpredictable habitats (Fig. 3a) [72, 159]. This finding, might be due to the fact that many temperate or arctic species have been only studied in the laboratory or exclusively during the winter season, and the predictability of torpor use for many temperate/arctic species is therefore unknown. Interestingly, a slightly higher proportion of daily heterotherms were unpredictable $(57 \%$ versus $46 \%$ for hibernators) but a combined total of $31 \%$ of the species were found to be data deficient. This latter finding indicates the need for further studies on freeranging animals, which was also one of the results of a large comparison of two heterothermy metrics by Boyles et al. [10]. One of the metrics from that study, the thermoregulatory scope, necessitated only a mean normothermic $\mathrm{T}_{\mathrm{b}}$ and a minimum torpid $\mathrm{T}_{\mathrm{b}}$, whereas the second, the heterothermy index, required continuous $\mathrm{T}_{\mathrm{b}}$ traces. The former had over ten times the number of species (or measures from different species) than the latter, although the authors admit to only being able to obtain a subset of available $\mathrm{T}_{\mathrm{b}}$ datasets. The amount of data we have on heterothermy in mammals is heavily skewed towards laboratory data, which often underestimates torpor use [160]. A large number of the data deficient' species were also found at the lower latitudes. This is not surprising, however, because, our knowledge of the physiology of tropical and sub-tropical mammals lags far behind that of temperate species [52, 59, 64].

\section{Conclusions: $T_{b}$ variability, heterothermy, and modelling}

Studies on the $T_{b}$ patterns and thermoregulation of freeranging animals have illustrated the effects, and sometimes confounding influences, of a number of factors including predation risk [150], presence of conspecifics [145], food availability [130, 161], competition [162] and extreme events $[50,51,153,163]$ on $\mathrm{T}_{\mathrm{b}}$. Yet, robust predictions of responses to climate change require an in-depth understanding of how animals exist in the wild $[4,8]$. The level of unpredictability in terms of $\mathrm{T}_{\mathrm{b}}$ control in mammals can make predictions more complicated, but not impossible. However, if we are to improve our ability to predict potential responses of mammals to a changing global climate, we need to improve our understanding of endothermic physiology. Large-scale 

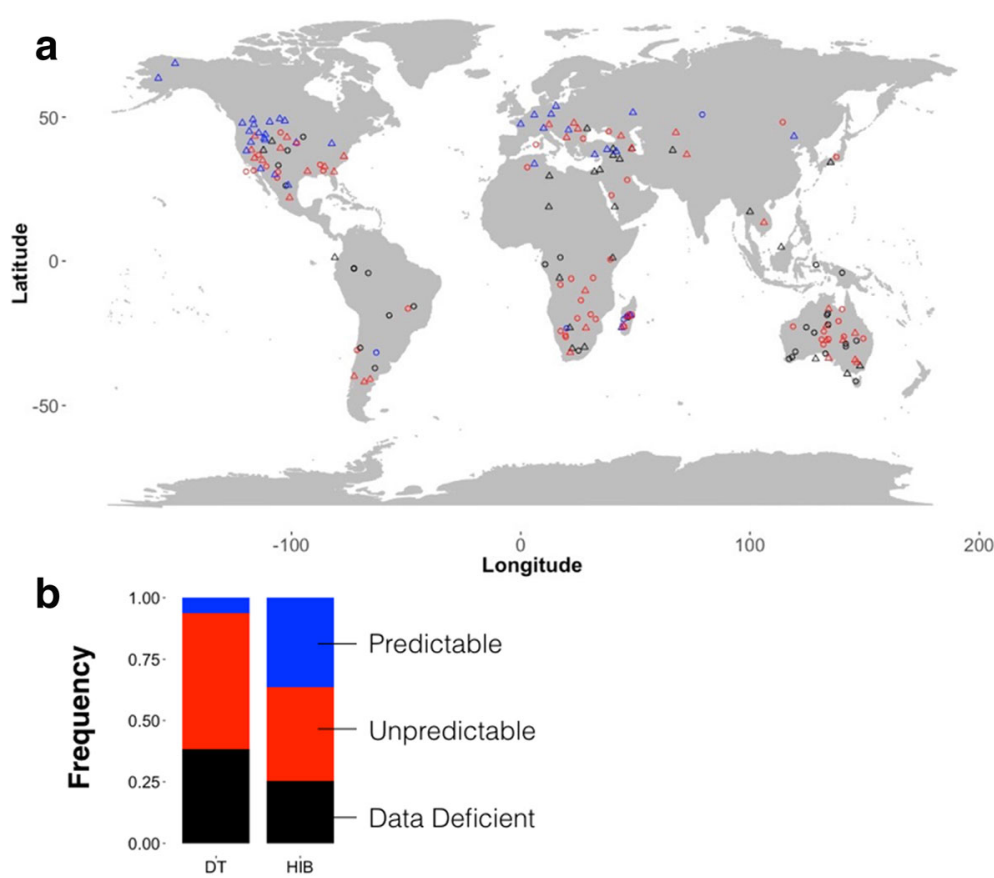

Fig. 3 a A distribution map of the daily heterotherms (DT, circles) and hibernators (HIB, triangles) reviewed in Ruf and Geiser [29]. Latitudes were taken from Table 1 of [29], longitudes from the PanTHERIA database [165], representing the mid-point of the species' range. Heterotherms with strictly seasonal, predictable torpor patterns are depicted in blue, those with unpredictable or spontaneous torpor use are marked in red and those that are data deficient (see text) in black. b Frequency distribution of each classification within daily heterotherms and hibernators

predictive models assessing the physiology of endotherms in relation to climate, and therefore their potential to be resilient (or not) in the face of global climate change have lagged behind the literature on ectotherms largely due to this fact. In particular, the lack of data on upper critical limits of the TNZ in mammals, or of thermal tolerance more broadly, as well as how these relate to free-ranging populations, severely hinders our current ability to build accurate models. The comprehensive study of responses to high $\mathrm{T}_{\mathrm{a}}$, both in the laboratory and the field is of pressing importance. Similarly, as extreme events and variability in $\mathrm{T}_{\mathrm{a}}$ are expected to increase in the coming decades [35, 164], more effort should be placed on quantifying the level of plasticity in a species response to environmental conditions [72]. To be able to include thermolability into predictive models we must first understand it. We believe that three steps are necessary to achieve this: 1 ) the level of $\mathrm{T}_{\mathrm{b}}$ variability, and its predictability, must be quantified in a range of species; 2) the energy and water costs of strict homeothermy versus any level of variability must be determined; and 3) the potential for variability must be modelled to provide predictions under both low and high variability scenarios. As has been mentioned previously, a first step would be to look to the ectotherm literature, where a large body of work has evaluated the costs and benefits to changing both the level (mean $\mathrm{T}_{\mathrm{b}}$ ) and the precision (variability) $[7,10,11]$, but we need to ensure that we include a variety of species representing different habitats, evolutionary histories, and lifehistories. Conceptual and predictive models taking into account the potential for variability, and phenotypic plasticity, will certainly prove to be more robust, and will provide a greater means of understanding endothermic physiology in the face of changing climates.

\section{Abbreviations \\ $T_{a}$ : Ambient temperature; $T_{b}$ : Core body temperature; TNZ: Thermoneutral zone}

\section{Acknowledgements}

The authors would like to thank Andrew McKechnie for inviting this review as well as two anonymous reviewers for helpful comments.

\section{Funding}

DLL was supported by the School of Biology and Ecology, University of Maine. JN was supported by an Endeavour Research Fellowship. CS was supported by an Australian Research Council Discovery Early Career Researcher Award.

\section{Availability of data and material}

Data available from the authors on request.

\section{Authors' contributions}

DLL conceived the initial idea for the paper. All authors developed, wrote and edited the manuscript, and coded the data. All authors read and approved the final manuscript.

Competing interests

The authors declare that they have no competing interests. 


\section{Consent for publication}

Not applicable.

\section{Ethics approval and consent to participate}

Not applicable.

\section{Author details}

${ }^{1}$ School of Biology and Ecology, University of Maine, Orono, ME, USA04469. ${ }^{2}$ Hawkesbury Institute for the Environment, Western Sydney University, Richmond 2753, NSW, Australia. ${ }^{3}$ Centre for Behavioural and Physiological Ecology, Zoology, University of New England, Armidale 2351, NSW, Australia.

Received: 14 July 2016 Accepted: 24 September 2016

Published online: 10 October 2016

\section{References}

1. Kearney M, Porter W. Mechanistic niche modelling: combining physiological and spatial data to predict species' ranges. Ecol Lett. 2009;12:334-50.

2. Buckley LB, Kingsolver JG. Functional and phylogenetic approaches to forecasting species' responses to climate change. Annu Rev Ecol Evol Syst. 2012;43:205-26.

3. Chown SL. Trait-based approaches to conservation physiology: forecasting environmental change risks from the bottom up. Philos Trans R Soc Lond B Biol Sci. 2012;367:1615-27.

4. Seebacher F, Franklin CE. Determining environmental causes of biological effects: the need for a mechanistic physiological dimension in conservation biology. Philos Trans R Soc Lond B Biol Sci. 2012;367:1607-14.

5. Urban MC, Bocedi G, Hendry AP, Mihoub J-B, Pe'er G, Singer A, Bridle JR, Crozier LG, De Meester L, Godsoe W, et al. Improving the forecast for biodiversity under climate change. Science. 2016;353.

6. Fuller A, Dawson T, Helmuth B, Hetem Robyn S, Mitchell D, Maloney Shane K. Physiological mechanisms in coping with climate change. Physiol Biochem Zool. 2010;83:713-20.

7. Angilletta Jr MJ, Cooper BS, Schuler MS, Boyles JG. The evolution of thermal physiology in endotherms. Front Biosci. 2010;2:861-81.

8. Huey RB, Kearney MR, Krockenberger A, Holtum JAM, Jess M, Williams SE Predicting organismal vulnerability to climate warming: roles of behaviour, physiology and adaptation. Philos Trans R Soc Lond B Biol Sci. 2012;367:1665-79.

9. Buckley LB, Hurlbert AH, Jetz W. Broad-scale ecological implications of ectothermy and endothermy in changing environments. Glob Ecol Biogeogr. 2012;21:873-85.

10. Boyles JG, Thompson AB, McKechnie AE, Malan E, Humphries MM, Careau V. A global heterothermic continuum in mammals. Glob Ecol Biogeogr. 2013;22:1029-39.

11. Boyles JG, Seebacher F, Smit B, McKechnie AE. Adaptive thermoregulation in endotherms may alter responses to climate change. Integr Comp Biol. 2011;51:676-90.

12. McCain CM, King SRB. Body size and activity times mediate mammalian responses to climate change. Glob Chang Biol. 2014;20:1760-9.

13. Rezende EL, Bacigalupe LD. Thermoregulation in endotherms: physiological principles and ecological consequences. J Comp Physiol B. 2015;85:709-27.

14. Tattersall GJ, Leite CA, Sanders CE, Cadena V, Andrade DV, Abe AS, Milsom WK. Seasonal reproductive endothermy in tegu lizards. Sci Adv. 2016:2:e1500951

15. Angilletta MJ. Thermal Adaptation: A Theoretical and Empirical Synthesis. Oxford: Oxford University Press; 2009

16. Tattersall GJ, Sinclair BJ, Withers PC, Fields PA, Seebacher F, Cooper CE, Maloney SK. Coping with thermal challenges: Physiological adaptations to environmental temperatures. Compr Physiol. 2012;2:2151-202.

17. Bartholomew GA. Body temperature and energy metabolism. In: Gordon MS, Bartholomew GA, Grinnell AD, Jorgensen CB, White FN, editors. Animal Physiology: Principles and Adaptations. Secondth ed. New York: Macmillan Publishing Co., Inc; 1972. p. 298-368.

18. Scholander PF, Hock R, Walters V, Irving L. Adaptation to cold in arctic and tropical mammals and birds in relation to body temperature, insulation, and basal metabolic rate. Biol Bull. 1950;99:259-71.

19. Porter WP, Gates DM. Thermodynamic equilibria of animals with environment. Ecol Monogr. 1969;39:227-44.

20. Porter WP, Kearney M. Size, shape, and the thermal niche of endotherms. Proc Natl Acad Sci U S A. 2009;106:19666-72.
21. Humphries MM, Umbanhowar J. Filtering environmental variability: Activity optimization, thermal refuges, and the energetic responses of endotherms to temperature. In: Vasseur DA, McCann KS, editors. The Impact of Environmental Variability on Ecological Systems, vol. 2. Netherlands: Springer; 2007. p. 61-87.

22. Porter W, Ostrowski S, Williams J. Modeling animal landscapes. Physiol Biochem Zool. 2010;83:705-12.

23. Glanville EJ, Seebacher F. Plasticity in body temperature and metabolic capacity sustains winter activity in a small endotherm (Rattus fuscipes). Comp Biochem Physiol A. 2010;155:383-91.

24. Shrestha AK, Wieren SE, Langevelde F, Fuller A, Hetem RS, Meyer L, Bie S, Prins $\mathrm{HHT}$. Larger antelopes are sensitive to heat stress throughout all seasons but smaller antelopes only during summer in an African semi-arid environment. Int J Biometeorol. 2013. doi:10.1007/s00484-012-0622-y.

25. Hetem RS, Maloney SK, Fuller A, Mitchell D. Heterothermy in large mammals: inevitable or implemented? Biol Rev. 2016;91:187-205.

26. Signer C, Ruf T, Arnold W. Hypometabolism and basking: the strategies of Alpine ibex to endure harsh over-wintering conditions. Funct Ecol. 2011;25:537-47.

27. Arnold W, Ruf T, Reimoser S, Tataruch F, Onderscheka K, Schober F. Nocturnal hypometabolism as an overwintering strategy of red deer (Cervus elaphus). Am J Physiol Regul Integr Comp Physiol. 2004;286:R174-81.

28. Heldmaier G, Ortmann S, Elvert R. Natural hypometabolism during hibernation and daily torpor in mammals. Respir Physiol Neurobiol. 2004;141:317-29.

29. Ruf T, Geiser F. Daily torpor and hibernation in birds and mammals. Biol Rev. 2015:90:891-926.

30. Staples JF. Metabolic flexibility: hibernation, torpor, and estivation. Compr Physiol. 2016;6:737-71.

31. Nagy KA. Seasonal water, energy and food use by free-living, arid-habitat mammals. Aust J Zool. 1994:42:55-63.

32. Tieleman $\mathrm{BI}$, Williams JB. The role of hyperthermia in the water economy of desert birds. Physiol Biochem Zool. 1999;72:87-100.

33. Degen AA. Ecophysiology of small desert mammals. Berlin: Springer; 1997.

34. Schmidt-Nielsen K, Schmidt-Nielsen B, Jarnum S, Houpt T. Body temperatures of the camel and its relation to water economy. Am J Physiol. 1956:188:103-12.

35. McKechnie AE, Wolf BO. Climate change increases the likelihood of catastrophic avian mortality events during extreme heat waves. Biol Lett. 2010;6:253-6.

36. Lovegrove BG. The evolution of endothermy in Cenozoic mammals: a plesiomorphic-apomorphic continuum. Biol Rev. 2012;87:128-62.

37. Humphries MM, Boutin S, Thomas DW, Ryan JD, Selman C, McAdam AG, Berteaux D, Speakman JR. Expenditure freeze: the metabolic response of small mammals to cold environments. Ecol Lett. 2005:8:1326-33.

38. Humphries MM, Careau V. Heat for nothing or activity for free? Evidence and implications of activity-thermoregulatory heat substitution. Integr Comp Biol. 2011:51:419-31.

39. Aschoff J, Pohl H. Rhythmic variations in energy metabolism. Fed Proc 1969:29:1541-52

40. Lovegrove BG. A phenology of the evolution of endothermy in birds and mammals. Biol Rev Camb Philos Soc. 2016. doi:10.1111/brv.12280.

41. Schleucher E, Prinzinger R. Heterothermia and torpor in birds: highly specialized physiologcial ability or just deep "nocturnal hypothermia"? The limitations of terminology. Acta Zool Sin. 2006;52(Supplement):393-6.

42. Moyer-Horner L, Mathewson PD, Jones GM, Kearney MR, Porter WP. Modeling behavioral thermoregulation in a climate change sentinel. Ecol Evol. 2015:5:5810-22.

43. Rey B, Halsey LG, Hetem RS, Fuller A, Mitchell D, Rouanet J-L. Estimating resting metabolic rate by biologging core and subcutaneous temperature in a mammal. Comp Biochem Physiol Part A Mol Integr Physiol. 2015;183:72-7.

44. Taylor CR, Johansen K, Bolis L, Aschoff J. The circadian rhythm of body temperature as a function of body size. In: A Companion to Animal Physiology. Cambridge: Cambridge University Press; 1982. p. 173-88.

45. Refinetti $\mathrm{R}$, Menaker $\mathrm{M}$. The circadian-rhythm of body temperature. Physiol Behav. 1992:51:613-37.

46. Clarke A, Rothery P. Scaling of body temperature in mammals and birds. Funct Ecol. 2008;22:58-67.

47. Robinson KW. Heat tolerances of Australian monotremes and marsupials. Aust J Biol Sci. 1954;7:348-60.

48. Morrison PR, Ryser FA. Weight and body temperature in mammals. Science. 1952;116:231-2. 
49. Refinetti R. Body temperature and behaviour of golden hamsters (Mesocricetus auratus) and ground squirrels (Spermophilus tridecemlineatus) in a thermal gradient. J Comp Physiol A. 1995;177:701-5.

50. Nowack J, Rojas AD, Körtner G, Geiser F. Snoozing through the storm: torpor use during a natural disaster. Sci Rep. 2015;5:11243.

51. Stawski C, Körtner G, Nowack J, Geiser F. The importance of mammalian torpor for survival in a post-fire landscape. Biol Lett. 2015;11:20150134.

52. Canale $\mathrm{Cl}$, Levesque $\mathrm{DL}$, Lovegrove BG. Tropical heterothermy: Does the exception prove the rule or force a re-definition? In: Ruf T, Bieber C, Arnold W, Millesi E, editors. Living in a Seasonal World: Thermoregulatory and Metabolic Adaptations. Heidelberg: Springer Berlin; 2012. p. 29-40.

53. Grigg GC, Beard LA, Augee ML. The evolution of endothermy and its diversity in mammals and birds. Physiol Biochem Zool. 2004;77:982-97.

54. Brice PH. Thermoregulation in monotremes: riddles in a mosaic. Aust J Zool. 2009;57:255-63.

55. Levesque DL, Lobban KD, Lovegrove BG. Effects of reproductive status and high ambient temperatures on the body temperature of a free-ranging basoendotherm. J Comp Physiol B. 2014;184:1041-53.

56. Oelkrug R, Goetze N, Exner C, Lee Y, Ganjam GK, Kutschke M, Müller S, Stöhr S, Tschöp MH, Crichton PG, et al. Brown fat in a protoendothermic mammal fuels eutherian evolution. Nat Commun. 2013:4:e2140.

57. White $C R$, Kearney MR. Determinants of inter-specific variation in basal metabolic rate. J Comp Physiol B. 2013;183:1-26.

58. Clarke A, Rothery P, Isaac NJB. Scaling of basal metabolic rate with body mass and temperature in mammals. J Anim Ecol. 2010;79:610-9.

59. Lovegrove BG. The influence of climate on the basal metabolic rate of small mammals: a slow-fast metabolic continuum. J Comp Physiol B. 2003;173:87-112.

60. Gerkema MP, Davies WIL, Foster RG, Menaker M, Hut RA. The nocturnal bottleneck and the evolution of activity patterns in mammals. Proc $\mathrm{R}$ Soc B. 2013:280:20130508.

61. Crompton AW, Taylor CR, Jagger JA. Evolution of homeothermy in mammals. Nature. 1978;272:333-6.

62. van der Vinne V, Gorter JA, Riede SJ, Hut RA. Diurnality as an energy-saving strategy: energetic consequences of temporal niche switching in small mammals. J Exp Biol. 2015;218:2585-93.

63. Levesque $\mathrm{DL}$, Lovegrove $\mathrm{BG}$. Increased homeothermy during reproduction in a basal placental mammal. J Exp Biol. 2014;217:1535-42.

64. Lovegrove BG, Canale $\mathrm{Cl}$, Levesque $\mathrm{DL}$, Fluch $\mathrm{G}$, Řeháková-Petrů M, Ruf T. Are tropical small mammals physiologically vulnerable to Arrhenius effects and climate change? Physiol Biochem Zool. 2014;87:30-45.

65. Malan A. The origins of hibernation: a reappraisal. In: Geiser F, Hulbert A, Nicol S, editors. Adaptations to the Cold. Armidale: University of New England Press; 1996. p. 1-6.

66. Aschoff J. Circadian control of body temperature. J Therm Biol. 1983;8:143-7.

67. Lovegrove BG, Heldmaier G, Ruf T. Perspectives of endothermy revisited The endothermic temperature-range. J Therm Biol. 1991;16:185-97.

68. Aschoff J. Thermal conductance in mammals and birds: Its dependence on body size and circadian phase. Comp Biochem Physiol Part A Mol Integr Physiol. 1981;69:611-9.

69. McNab BK. On the utility of uniformity in the definition of basal rate of metabolism. Physiol Zool. 1997;70:718-20.

70. Lovegrove BG, Smith GA. Is "nocturnal hypothermia" a valid physiological concept in small birds?: a study on Bronze Mannikins (Spermestes cuccullatus). Ibis. 2003;145:547-57.

71. McKechnie $A E$, Lovegrove BG. Avian facultative hypothermic responses: a review. Condor. 2002;104:705-24.

72. Canale $\mathrm{Cl}$, Henry PY. Adaptive phenotypic plasticity and resilience of vertebrates to increasing climatic unpredictability. Clin Res. 2010;43:135-47.

73. van der Vinne V, Riede SJ, Gorter JA, Eijer WG, Sellix MT, Menaker M, Daan S, Pilorz $V$, Hut RA. Cold and hunger induce diurnality in a nocturnal mammal. Proc Natl Acad Sci U S A. 2014;111:15256-60.

74. Kronfeld-Schor N, Dayan T. Activity patterns of rodents: the physiological ecology of biological rhythms. Biol Rhythm Res. 2008;39:193-211.

75. Hut RA, Pilorz V, Boerema AS, Strijkstra AM, Daan S. Working for food shifts nocturnal mouse activity into the day. PLoS One. 2011;6:e17527.

76. Bondarenco A, Körtner G, Geiser F. Hot bats: extreme thermal tolerance in a desert heat wave. Naturwissenschaften. 2014;101:679-85.

77. Bartholomew GA, Rainy M. Regulation of body temperature in rock hyrax, Heterohyrax brucei. J Mammal. 1971;52:81-95.

78. Riek A, Geiser F. Allometry of thermal variables in mammals: consequences of body size and phylogeny. Biol Rev. 2013;88:564-72.
79. Whitfield MC, Smit B, McKechnie AE, Wolf BO. Avian thermoregulation in the heat: scaling of heat tolerance and evaporative cooling capacity in three southern African arid-zone passerines. J Exp Biol. 2015;218:1705-14.

80. McKechnie AE, Smit B, Whitfield MC, Noakes MJ, Talbot WA, Garcia M, Gerson AR, Wolf BO. Avian thermoregulation in the heat: evaporative cooling capacity in an archetypal desert specialist, Burchell's sandgrouse (Pterocles burchelli). J Exp Biol. 2016;219:2137-44.

81 Zub K, Fletcher QE, Szafrańska PA, Konarzewski M. Male weasels decrease activity and energy expenditure in response to high ambient temperatures. PLoS One. 2013;8:e72646.

82 Withers PC, Cooper CE, Larcombe AN. Environmental correlates of physiological variables in marsupials. Physiol Biochem Zool. 2006;79:437-53.

83 Nicoll ME, Thompson SD. Basal metabolic rates and energetics of reproduction in therian mammals: marsupials and placentals compared. In: Loudon ASI, Racey PA, editors. Reproductive Energetics in Mammals, vol. 57. Oxford: Clarendon; 1987. p. 7-27.

84 Stephenson PJ, Racey PA. Seasonal variation in resting metabolic rate and body temperature of streaked tenrecs, Hemicentetes nigriceps and $\mathrm{H}$. semispinosus (Insectivora: Tenrecidae). J Zool. 1994;232:285-94.

85 Brice $P$. Heat tolerance and cold indifference in the short-beaked echidna, Tachyglossus aculeatus: Body temperature management in a mammalian constitutional eurytherm. St Lucia: University of Queensland, School of Biological Sciences; 2008.

86 Brice PH, Grigg GC, Beard LA, Donovan JA. Patterns of activity and inactivity in echidnas (Tachyglossus aculeatus) free-ranging in a hot dry climate: correlates with ambient temperature, time of day and season. Aust J Zool. 2002;50:461-75.

87 Kuchel $L$. The energetics and patterns of torpor in free-ranging Tachyglossus aculeatus from a warm-temperate climate. St Lucia: PhD. University of Queensland, School of Integrative Biology; 2003.

88 Wooden KM, Walsberg GE. Body temperature and locomotor capacity in a heterothermic rodent. J Exp Biol. 2004;207:41-6.

89 Rojas AD, Körtner G, Geiser F. Cool running: locomotor performance at low body temperature in mammals. Biol Lett. 2012;8:868-70.

90 Noakes MJ, Smit B, Wolf BO, McKechnie AE. Thermoregulation in African Green Pigeons (Treron calvus) and a re-analysis of insular effects on basal metabolic rate and heterothermy in columbid birds. J Comp Physiol B. 2013;183:969-82.

91 Boyles JG, Smit B, McKechnie AE. Does use of the torpor cut-off method to analyze variation in body temperature cause more problems than it solves? J Therm Biol. 2011;36:373-5.

92 Kobbe S, Nowack J, Dausmann K. Torpor is not the only option: seasonal variations of the thermoneutral zone in a small primate. J Comp Physiol B. 2014:184:789-97.

93 Holloway J, Geiser F. Seasonal changes in the thermoenergetics of the marsupial sugar glider, Petaurus breviceps. J Comp Physiol B. 2001;171:643-50.

94 Levesque DL, Tattersall GJ. Seasonal torpor and normothermic energy metabolism in the Eastern chipmunk (Tamias striatus). J Comp Physiol B. 2010;180:279-92.

95 Lovegrove BG. Seasonal thermoregulatory responses in mammals. J Comp Physiol B. 2005;175:231-47.

96 Mzilikazi N, Lovegrove BG. Reproductive activity influences thermoregulation and torpor in the pouched mouse, Saccostomus campestris. J Comp Physiol B. 2002;172:7-16.

97 Dausmann KH, Glos J, Heldmaier G. Energetics of tropical hibernation. J Comp Physiol B. 2009;179:345-57.

98 Kobbe S, Ganzhorn JU, Dausmann KH. Extreme individual flexibility of heterothermy in free-ranging Malagasy mouse lemurs (Microcebus griseorufus). J Comp Physiol B. 2011;181:165-73.

99 Dausmann $\mathrm{KH}$, Wein J, Turner JM, Glos J. Absence of heterothermy in the European red squirrel (Sciurus vulgaris). Mamm Biol. 2013;78:332-5.

100 Arnold W, Ruf T, Kuntz R. Seasonal adjustment of energy budget in a large wild mammal, the Przewalski horse (Equus ferus przewalskii) II. Energy expenditure. J Exp Biol. 2006;209:4566-73.

101 Glanville EJ, Seebacher F. Advantage to lower body temperatures for a small mammal (Rattus fuscipes) experiencing chronic cold. J Mammal. 2010;91:1197-204

102 Humphries MM, Thomas DW, Kramer DL. The role of energy availability in mammalian hibernation: a cost-benefit approach. Physiol Biochem Zool. 2003:76:165-79.

103 Prendergast BJ, Freeman DA, Zucker I, Nelson RJ. Periodic arousal from hibernation is necessary for initiation of immune responses in ground squirrels. Am J Physiol Regul Integr Comp Physiol. 2002;282:R1054-62. 
104 Luis AD, Hudson PJ. Hibernation patterns in mammals: a role for bacterial growth? Funct Ecol. 2006;20:471-7.

105 Carey HV, Andrews MT, Martin SL. Mammalian hibernation: cellular and molecular responses to depressed metabolism and low temperature. Physiol Rev. 2003;83:1153-81.

106 Arendt T, Stieler J, Strijkstra AM, Hut RA, Rüdiger J, Van der Zee EA, Harkany T, Holzer M, Härtig W. Reversible paired helical filament-like phosphorylation of tau is an adaptive process associated with neuronal plasticity in hibernating animals. J Neurosci. 2003;23:6972-81.

107 McAllan BM, Geiser F. Torpor during reproduction in mammals and birds: dealing with an energetic conundrum. Integr Comp Biol. 2014;54:516-32.

108 Fietz J, Schlund W, Dausmann KH, Regelmann M, Heldmaier G. Energetic constraints on sexual activity in the male edible dormouse (Glis glis). Oecologia. 2004;138:202-9.

109 Barnes BM, Kretzmann M, Licht P, Zucker I. The influence of hibernation on testis growth and spermatogenesis in the Golden-mantled ground-squirrel, Spermophilus lateralis. Biol Reprod. 1986;35:1289-97.

110 Nowack J, Delesalle M, Stawski C, Geiser F. Can hibernators sense and evade fires? Olfactory acuity and locomotor performance during deep torpor. Sci Nat. 2016;103:1-7.

111 Carey HV, Frank CL, Seifert JP. Hibernation induces oxidative stress and activation of NF-kappa B in ground squirrel intestine. J Comp Physiol B. 2000;170:551-9.

112 Orr AL, Lohse LA, Drew KL, Hermes-Lima M. Physiological oxidative stress after arousal from hibernation in Arctic ground squirrel. Comp Biochem Physiol A. 2009;153:213-21.

113 Dausmann KH, Nowack J, Kobbe S, Mzilikazi N. Afrotropical heterothermy: a continuum of possibilities. In: Ruf T, Bieber C, Arnold W, Millesi E, editors. Living in a Seasonal World: Thermoregulatory and Metabolic Adaptations. Heidelberg: Springer Berlin; 2012. p. 13-27.

114 Lovegrove BG. A single origin of heterothermy in mammals. In: Ruf T, Bieber C, Arnold W, Millesi E, editors. Living in a Seasonal World: Thermoregulatory and Metabolic Adaptations. Berlin: Springer; 2012. p. 3-11.

115 Naya DE, Spangenberg L, Naya H, Bozinovic F. Thermal conductance and basal metabolic rate are part of a coordinated system for heat transfer regulation. Proc R Soc B. 2013;280:20131629.

116 Hochachka PW, Somero GN. Biochemical adaptation: mechanism and process in physiological evolution. New York: Oxford University Press; 2002.

117 Willis CKR, Brigham RM. Defining torpor in free-ranging bats: experimental evaluation of external temperature-sensitive radiotransmitters and the concept of active temperature. J Comp Physiol B. 2003;173:379-89.

118 Mzilikazi N, Lovegrove BG, Ribble DO. Exogenous passive heating during torpor arousal in free-ranging rock elephant shrews, Elephantulus myurus. Oecologia. 2002;133:307-14.

119 Warnecke L, Geiser F. Basking behaviour and torpor use in free-ranging Planigale gilesi. Aust J Zool. 2009;57:373-5.

120 Warnecke L, Geiser F. The energetics of basking behaviour and torpor in a small marsupial exposed to simulated natural conditions. J Comp Physiol B. 2010;180:437-45.

121 Geiser F, Gasch K, Bieber C, Stalder GL, Gerritsmann H, Ruf T. Basking hamsters reduce resting metabolism, body temperature and energy costs during rewarming from torpor. J Exp Biol. 2016;219:2166-72.

122 Thompson ML, Mzilikazi N, Bennett NC, McKechnie AE. Solar radiation during rewarming from torpor in elephant shrews: supplementation or substitution of endogenous heat production? PLoS One. 2015;10:e0120442.

123 Lovegrove BG, Kortner G, Geiser F. The energetic cost of arousal from torpor in the marsupial Sminthopsis macroura: benefits of summer ambient temperature cycles. J Comp Physiol B. 1999;169:11-8.

124 Turbill C, Kortner G, Geiser F. Timing of the daily temperature cycle affects the critical arousal temperature and energy expenditure of lesser long-eared bats. J Exp Biol. 2008;211:3871-8.

125 Geiser F, Goodship N, Pavey CR. Was basking important in the evolution of mammalian endothermy? Naturwissenschaften. 2002;89:412-4.

126 Warnecke L, Turner JM, Geiser F. Torpor and basking in a small arid zone marsupial. Naturwissenschaften. 2008;95:73-8.

127 Geiser F, Pavey CR. Basking and torpor in a rock-dwelling desert marsupial: survival strategies in a resource-poor environment. J Comp Physiol B. 2007;177:885-92

128 Currie S, Noy K, Geiser F. Passive rewarming from torpor in hibernating bats: minimizing metabolic costs and cardiac demands. Am J Physiol Regul Integr Comp Physiol. 2015;308:R34-41.
129 Dausmann KH, Glos J, Ganzhorn JU, Heldmaier G. Hibernation in the tropics: lessons from a primate. J Comp Physiol B. 2005;175:147-55.

130 Vuarin P. Henry P-Y. Field evidence for a proximate role of food shortage in the regulation of hibernation and daily torpor: a review. J Comp Physiol B. 2014;184:683-97.

131 Hallam SL, Mzilikazi N. Heterothermy in the southern African hedgehog, Atelerix frontalis. J Comp Physiol B. 2011;181:437-45.

132 Vuarin P, Dammhahn M, Henry PY. Individual flexibility in energy saving: body size and condition constrain torpor use. Funct Ecol. 2013;27:793-9.

133 Stawski C, Geiser F. Fat and fed: frequent use of summer torpor in a subtropical bat. Naturwissenschaften. 2010;97:29-35.

134 Dausmann KH. Flexible patterns in energy savings: heterothermy in primates. J Zool. 2014;292:101-11.

135 Geiser F. The role of torpor in the life of Australian arid zone mammals. Aust Mammal. 2004:26:125-34.

136 Schmid J, Speakman JR. Daily energy expenditure of the grey mouse lemur (Microcebus murinus): a small primate that uses torpor. J Comp Physiol B. 2000;170:633-41.

137 Withers PC, Cooper CE, Nespolo RF. Evaporative water loss, relative water economy and evaporative partitioning of a heterothermic marsupial, the monito del monte (Dromiciops gliroides). J Exp Biol. 2012;215:2806-13.

138 Geiser F, Christian N, Cooper C, Körtner G, McAllan BM, Pavey C, Turner JM, Warnecke L, Willis CKR, Brigham RM. Torpor in marsupials: recent advances. In: Lovegrove BG, McKechnie AE, editors. Hypometabolism in Animals: Torpor, Hibernation and Cryobiology. Pietermaritzburg: Interpak Books; 2008. p. 297-306.

139 Körtner G, Pavey CR, Geiser F. Thermal biology, torpor, and activity in free-living mulgaras in arid zone Australia during the winter reproductive season. Physiol Biochem Zool. 2008;81:442-51.

140 Willis CKR, Brigham RM, Geiser F. Deep, prolonged torpor by pregnant, free-ranging bats. Naturwissenschaften. 2006;93:80-3.

141 Stawski C, Willis C, Geiser F. The importance of temporal heterothermy in bats. J Zool (Lond). 2014;292:86-100.

142 van Breukelen F, Martin SL. The Hibernation Continuum: Physiological and Molecular Aspects of Metabolic Plasticity in Mammals. Physiology. 2015;30:273-81.

143 Williams CT, Barnes BM, Kenagy GJ, Buck CL. Phenology of hibernation and reproduction in ground squirrels: integration of environmental cues with endogenous programming. J Zool. 2014;292:112-24.

144 Zervanos SM, Maher CR, Waldvogel JA, Florant GL. Latitudinal differences in the hibernation characteristics of woodchucks (Marmota monax). Physiol Biochem Zool. 2010;83:135-41.

145 Lehmer EM, Savage LT, Antolin MF, Biggins DE. Extreme plasticity in thermoregulatory behaviors of free-ranging black-tailed prairie dogs. Physiol Biochem Zool. 2006;79:454-67.

146 Young PJ. Hibernating patterns of free-ranging Columbian ground-squirrels. Oecologia. 1990;83:504-11.

147 Buck CL, Barnes BM. Annual cycle of body composition and hibernation in free-living arctic ground squirrels. J Mammal. 1999:80:430-42.

148 Turbill C. Thermoregulatory behavior of tree-roosting chocolate wattled bats (Chalinolobus morio) during summer and winter. J Mammal. 2006;87:318-23.

149 Wojciechowski MS, Jefimow M, Tegowska E. Environmental conditions, rather than season, determine torpor use and temperature selection in large mouseeared bats (Myotis myotis). Comp Biochem Physiol A. 2007;147:828-40.

150 Bieber C, Ruf T. Summer dormancy in edible dormice (Glis glis) without energetic constraints. Naturwissenschaften. 2009;96:165-71.

151 Vivier L, Van Der Merwe M. The incidence of torpor in winter and summer in the Angolan free-tailed bat, Mops condylurus (Microchiroptera: Molossidae), in a subtropical environment, Mpumulanga, South Africa. Afr Zool. 2007:42:50-8.

152 Turner J, Warnecke L, Körtner G, Geiser F. Opportunistic hibernation by a free-ranging marsupial. J Zool. 2011;286:277-84.

153 Doucette LI, Brigham RM, Pavey CR, Geiser F. Prey availability affects daily torpor by free-ranging Australian owlet-nightjars (Aegotheles cristatus). Oecologia. 2012;169:361-72.

154 Nowack J, Dausmann KH. Can heterothermy facilitate the colonization of new habitats? Mammal Rev. 2015:45:117-27.

155 Turbill C, Prior S. Thermal climate-linked variation in annual survival rate of hibernating rodents: shorter winter dormancy and lower survival in warmer climates. Funct Ecol. 2016;30:1366-72.

156 Pretzlaff I, Dausmann KH. Impact of climatic variation on the hibernation physiology of Muscardinus avellanarius. In: Ruf T, Bieber C, Arnold W, Millesi 
E, editors. Living in a Seasonal World: Thermoregulatory and Metabolic Adaptations. Heidelberg: Springer Berlin; 2012. p. 85-97.

157 Geiser F, Kenagy G. Torpor duration in relation to temperature and metabolism in hibernating ground squirrels. Physiol Zool. 1988;61:442-9.

158 Reeder DM, Frank CL, Turner GG, Meteyer CU, Kurta A, Britzke ER, Vodzak ME, Darling SR, Stihler CW, Hicks AC. Frequent arousal from hibernation linked to severity of infection and mortality in bats with white-nose syndrome. PLoS One. 2012;7:e38920.

159 Lovegrove BG. The power of fitness in mammals: perceptions from the African slipstream. Physiol Biochem Zool. 2006;79:224-36.

160 Geiser F, Holloway JC, Körtner G, Maddocks TA, Turbill C, Brigham RM. Do patterns of torpor differ between free-ranging and captive mammals and birds. In: Heldmaier G, Klingenspor M, editors. Life In The Cold: 11th International Hibernation Symposium. Berlin: Springer; 2000. p. 95-102.

161 Zervanos SM, Maher CR, Florant GL. Effect of body mass on hibernation atrategies of woodchucks (Marmota monax). Integr Comp Biol. 2013;54:443-51.

162 Levy O, Dayan T, Kronfeld-Schor N. Interspecific competition and torpor in golden spiny mice: two sides of the energy-acquisition coin. Integr Comp Biol. 2011;51:441-8.

163 Nowack J, Cooper CE, Geiser F. Cool echidnas survive the fire. Proc R Soc Lond B Biol Sci. 2016. doi:10.1098/rspb.2016.0382..

164 Vasseur DA, DeLong JP, Gilbert B, Greig HS, Harley CDG, McCann KS, Savage $\checkmark$, Tunney TD, O'Connor MI. Increased temperature variation poses a greater risk to species than climate warming. Proc R Soc B. 2014;281:20132612.

165 Jones KE, Bielby J, Cardillo M, Fritz SA, O'Dell J, Orme CDL, Safi K, Sechrest W, Boakes EH, Carbone C. PanTHERIA: a species-level database of life history, ecology, and geography of extant and recently extinct mammals. Ecology. 2009:90:2648.

\section{Submit your next manuscript to BioMed Central and we will help you at every step:}

- We accept pre-submission inquiries

- Our selector tool helps you to find the most relevant journal

- We provide round the clock customer support

- Convenient online submission

- Thorough peer review

- Inclusion in PubMed and all major indexing services

- Maximum visibility for your research

Submit your manuscript at www.biomedcentral.com/submit 